\title{
Monetary and Fiscal Actions: A Test of Their Relative Importance in Economic Stabilization - Reply
}

T HE "COMMENT" by Frank de Leeuw and John Kalchbrenner is in reference to an earlier article of ours in which we presented evidence bearing on familiar statements regarding the relative importance of monetary and fiscal actions in economic stabilization. In this "Reply" we present additional analysis and evidence relating directly to the issues they have raised.

\section{Summary of Issues Raised}

In our November 1968 article we estimated the response of total spending in the economy (an endogenous or dependent variable) to changes in alternative summary measures of monetary and fiscal actions (exogenous or independent variables). De Leeuw and Kalchbrenner suggest two criteria for choosing exogenous policy variables: (1) the variables must be under the control of policymakers; and (2) the variables must not be "terribly sensitive to current movements in the endogenous variables." They say that "failure to meet this second require. ment has been a major criticism of regressions of GNP on the money supply." The use of the money supply as a measure of the influence of monetary actions will be discussed briefly at the end of this Reply.

Regarding the measures of fiscal actions, de Leeuw and Kalchbremer recommend adjusting the full-employment tax receipts variable for changes in the price level in order to eliminate the induced upward bias in tax receipts caused by inflation. ${ }^{1}$ We accept

1The desire to eliminate this factor assumes that the goverrment has not intentionally undertaken inflationary policies in order to finance government spending, as an alternative to raising tax rates or borrowing. This assumption would obviously not have been valid for post-World War 1 Germany. this recommendation by de Leeuw and Kalchbrenner and observe, as they do and as their equation 2 shows, that this modification does not affect the conclusion reached in our original article regarding the relative strength and reliability of monetary actions versus fiscal actions.

De Leeuw and Kalchbrenner state their principal concern is with whether or not the monetary base is exogenous in the statistical sense. They define the base as the sum of three "components"; unborrowed reserves; borrowed reserves, and currency. Their definition of the base consists of a very special decomposition of the uses of the monetary base, in contrast to the usually accepted definition of uses of the base. They make no mention in their "Comment" of the sources of the monetary base which shows the base as being derived from a consolidated Treasury and Federal Reserve balance sheet. This failure to distinguish sources of the base from uses is a fundamental point of difference between these critics and ourselves. Before we discuss their conception of the base further, we will complete this summary of their procedures and results.

They suggest that reserves borrowed from the Federal Reserve by member banks might be subtracted from the monetary base, and they present regression results in which they have done so. They advance that the criterion for including or excluding borrowings as a part of the base depends on whether or not "there is a strong tendency for movements in borrowing to be offset by movements in some other component of the base." They say that if there is such an offset tendency, then borrowing should not be excluded from the base. They then exclude borrowing 
from the base without presenting any evidence indicating whether or not there is such an offset. Furthermore, the results obtained when they substitute the base minus borrowing (their equation 2) for the monetary base (their equation 1 and our equation 1.4 in Table I of our original article) do not alter any of the conclusions we reached regarding the relative strength and reliability of monetary and fiscal actions.

The more important criticism by de Leeuw and Kalchbrenner stems from the results they obtained by subtracting both member bank borrowings and currency held by the public from the monetary base in order to obtain an alternative measure of monetary influence, which they call unborrowed reserves (Ru). They recommend subtracting currency held by the public from the monetary base for reasons similar to those for excluding borrowed reserves. They admit that their own criterion for exclusion of currency may not be confirmed statisically because of an "automatic" offset when the public obtains currency from banks. However, they argue that the central bank does not pay attention to currency movements, but rather they imply the Federal Reserve has intentionally determined the growth of "unborrowed reserves" over time and "offsets" any increased growth in currency by supplying more unborrowed reserves. We find this contention a highly questionable description of the Federal Reserve's behavior and intentions. But this issue is irrelevant because of their failure to distinguish between sources and uses of the monctary base.

The results obtained by de Leeuw and Kalchbrenner by substituting $R u$ for the base are reported as equation 3 in their Table I. As that equation shows, $\mathrm{Ru}$ is either inferior to the monetary base as a measure of monetary actions (the coefficients are statistically nonsignificant), or if $R u$ is the appropriate measure of monetary actions, there is little response of GNP to such actions. Also, both measures of fiscal actions (high-employment expenditures and receipts) indicate a stronger influence on GNP when the measure of monetary actions ( $\mathrm{Ru}$ ) is nonsignificant.

\section{Reply to Issues Raised}

The authors of the Comment raise some valid and important considerations regarding the statistical procedures employed in our original study. However, they overlook some equally valid and important considerations from the point-of-view of economic theory.
Variables used to test economic hypotheses must be relevant to the hypotheses. Their process of "peeling" the monetary base (first subtracting borrowings from Reserve Banks and then currency held by others than banks) in arriving at the concept "unborrowed reserves" may make sense statistically under special conditions, but this process has no economic relevance within the context of the customary body of economic theory which has evolved around the monetary base. We now will examine our contention regarding their use of unborrowed reserves as a summary measure of monetary actions, as well as some of the statistical considerations they advance for such use.

Monetary Base - As noted above, de Leeuw and Kalchbrenner define the monetary base as the sum of "unborrowed" reserves, reserves borrowed from the Federal Reserve, and currency held by the public. They overlook the fact that the base is derived from a consolidated balance sheet of Treasury and Federal Reserve monetary accounts and consequently make no reference to the sources of the base. ${ }^{2}$ Both the sources and the customary definition of uses of the base, along with de Leeuw and Kalchbrenner's special treatment of the uses, are presented in Table I.

The largest component of the sources of the monetary base is Federal Reserve holdings of U.S. Government securities, and variation in this component over time has dominated the variation in the base. ${ }^{3}$ It is true that other source components of the base are not directly controlled by the Federal Reserve, yet changes in these other components are always readily known, and the System can, by open market purchases or sales, completely "offset" any of the relatively small movements in any of these other source components of the base (including discounts and advances which includes member banks' borrowings from the Federal Reserve). If the System observes changes in other source components and chooses not to offset them, the Federal Reserve has caused a change in the base the same as when the System buys or sells securities and other components are unchanged. Consequently, the Federal Reserve, through its open market operations, determines the source side of the monetary base.

\footnotetext{
¿See Leonall C. Andersen and Jerry L. Jordan, "The Monetary Base - Explanation and Analytical Use" in the August 1968 issue of this Review.

3For further discussion of and evidence concerning Federal Reserve control over various monetary aggregates, includling the monetary base, see an article by Michael $W$. Keran and Christopher T. Babb, forthcoming in this Review.
} 


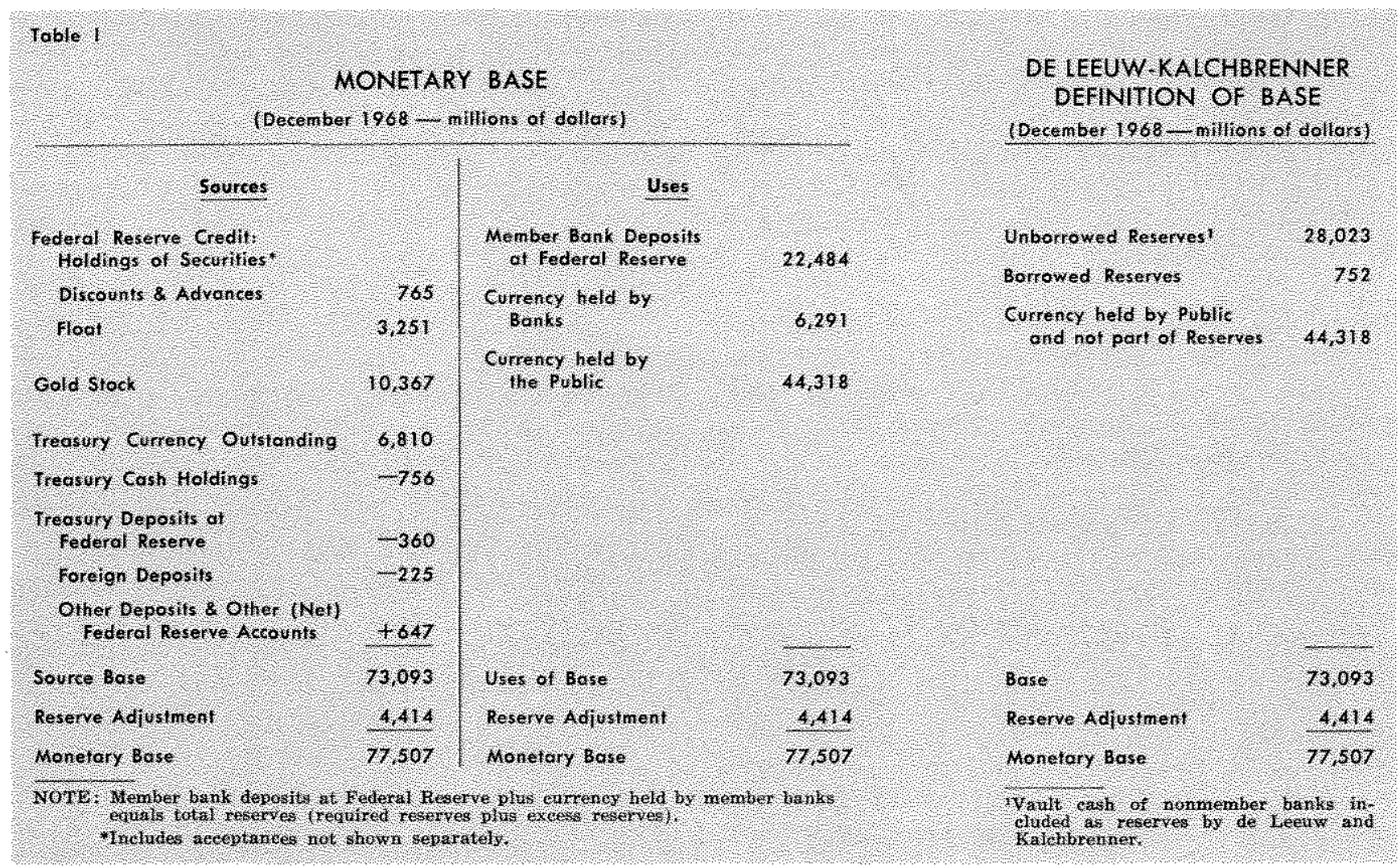

Since the base is derived from a balance sheet as in Table $I$ and since the uses (liabilities) side of the balance sheet must equal the sources (assets) side, the Federal Reserve determines the total size of the base through its open market purchases and sales of securities. Banks and the public determine the allocation between reserves and currency; these are uses of the base.

The authors of the Comment divide the reserve uses of the monetary base into borrowed and unborrowed reserves. They then treat currency and these two reserve classifications as sources ${ }^{4}-$ that is, a change in any one of the three, magnitudes changes the base by exactly the same amount - and question the exogenous character of these so-called sources. This treatment of uses as sources in discussing the statistical requirements of regressions using the monetary base leads our critics to accept an irrelevant exogenous measure of monetary actions. The proper procedure, if one were interested in finding a relevant exogenous variable, would be to examine the sources of the base presented in Table $I$.

4This confusion is prevalent among economists. In many studies reserves and currency are summed, providing a quick and ready way of developing a time series of the base. Nevertheless, the sum of the sources listed in Table I actually determines the magnitude of the base.
For these reasons we do not accept their procedure of "peeling" the monetary base in order to arrive at a statistically pure exogenous measure of monetary actions. However, we will examine further some of the arguments they advance.

Exclusion of Borrowings - A reason often given for excluding borrowed reserves (which have averaged less than one-half billion dollars in recent years) from total reserves (presently about $\$ 27$ billion) or from the monetary base (presently about $\$ 77$ billion) is the contention that the effect of borrowed reserves on bank credit or deposit expansion is different than the effect of "unborrowed" reserves. This contention implies that banks hold more excess reserves when their borrowings are greater than when smaller.

The "multiple expansion" of deposits by the banking system does not depend on the source of the additional reserves acquired by the banking system. Data for the banking system clearly shows that when total reserves have increased, deposits have increased by a multiple. Whether the additional reserves were borrowed by the banks or otherwise acquired does not make any discernible difference. Reserves borrowed by one bank when diffused throughout the banking system cannot be distinguished by any other bank from unborrowed reserves. 
As noted earlier, de Leeuw and Kalchbrenner advance a statistical criterion for excluding borrowed reserves from the base. They do not provide an economic argument for doing so, nor do they present any empirical evidence. They merely contend that if there is an "offset" between "unborrowed" reserves and borrowed reserves, the borrowing should not be excluded from the base (or from total reserves). In order to test whether or not there is a negative correlation or "offset" between borrowed (Rb) and unborrowed reserves ( $\mathrm{Ru}$ ) we estimated a regression equation for the period $\mathrm{I} / 53-\mathrm{II} / 68$ using seasonally adjusted quarterly data. The results were:

$$
\Delta \mathrm{Ru}=.179-1.065 \Delta \mathrm{Rb} .
$$

The simple correlation coefficient between $\Delta \mathrm{Rb}$ and $\Delta R u$ is -.63 and the $R^{2}$ is .40 .

These results indicate very clearly that there was a strong negative "offset" between borrowed and unborrowed reserves in the 15 -year test period. Consequently, there is no justification, either theoretical or statistical, for excluding member bank borrowing from the monetary base (or from total reserves) as a measure of the influence of monetary actions on economic activity. In fact, these results indicate that it is inappropriate to use "unborrowed reserves" as an exogenous measure of monetary actions since a large share of the changes in this variable is associated with offsetting movements in borrowed reserves.

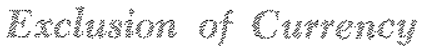

We argued above that the monetary authorities control the total monetary base through their control over the sources components of the base. Consequently, on theoretical grounds it is inappropriate to exclude either member bank borrowings or currency held by the public from the uses of the base. De Leeuw and Kalchbrenner did not report statistical results indicating whether borrowings should be excluded or not (as we have done above), nor did

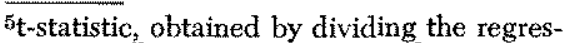
sion coefficient by the standard error. they report results indicating the effects of excluding currency held by the public from the monetary base, but not excluding borrowings. Subtracting currency held by the public from the base creates a measure of "total reserves" which is adjusted for changes in reserve requirements and includes vault cash of nonmember commercial banks (a relatively small and invariant magnitude). Total reserves also are relevant in many theories in monetary economics and, therefore, are a potential summary measure of monetary actions.

The results obtained using this measure of total reserves (TR) as a measure of monetary influence instead of the base are reported in Table II along with the results obtained using the monetary base. The results for the two equations are very similar, and the use of total reserves as a summary measure of monetary influence does not yield any different conclusions from those presented in our November article.

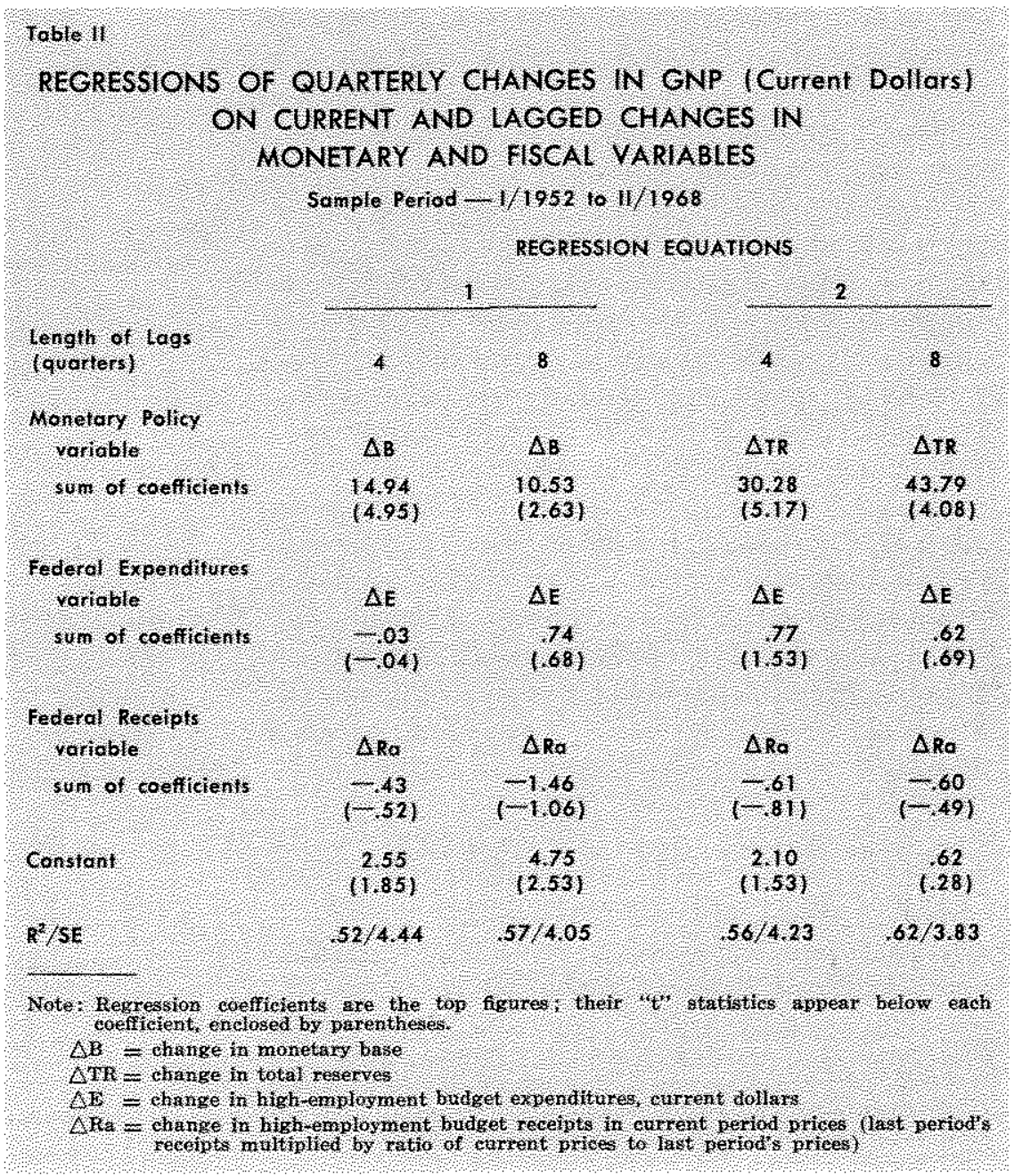


If de Leeuw and Kalchbrenner had excluded currency held by the public from the base, but had not excluded borrowings, their results would have been sufficiently similar to those obtained using total base or the money supply that none of the major conclusions of our original article would be changed.

\section{Oher wastess}

De Leeuw and Kalchbrenner do not discuss the use of the money supply as an indicator of monetary influence because, they imply, the series is sensitive to current movements in income. Their statement can be restated as a hypothesis that quarter-to-quarter changes in the money stock are strongly influenced by current or previous changes in income. This issue has been debated at considerable length on other occasions and can best be discussed within the context of a money supply model. ${ }^{6}$

Another point raised by de Leeuw and Kalch. bremner is that it is difficult to find variables which meet both definitions of exogenous since "policymak" ers themselves are naturally influenced in their decisions by current developments." An example will illustrate their point. Assume the monetary base is under the absolute control of the policymakers and that there is a very close one-way causal relation from changes in the base to changes in income. Given this assumption, if policymakers' decisions regarding changes in the base are made with the intent of achieving some desired growth of income as opposed to an observed growth, then it can be concluded that, in a sense, the base is "endogenous" or influenced by current economic developments. We would accept this contention, but would point out that the base is still statistically exogenous. Moreover, we submit that such a distinction is totally irrelevant, since the policymakers can know in advance what the effect of their actions will be, and can confidently influence economic activity without being concerned about any misleading "feedback" effects on their indicator variable.

\footnotetext{
6For example see A. E. Burger, "A Summary of the BrunnerMeltzer Non-Linear Money Supply Hypothesis," Working Paper No. 7, Federal Reserve Bank of St. Louis, revised, May 1969. The reader should also consult another article in the May 1969 issue of this Review, "Controlling Money," by Professor Allan H. Meltzer, and an article in the July 1968 issue of this Review, "The Role of Money and Monetary Policy," by Professor Karl Brunner (especially pp. 15-18). The theory and evidence presented in these papers allow the authors to conclude that changes in the money stock are strongly dominated by changes in the monetary base and that the monetary authorities can exercise very close control over money through their control over the base.
}

\section{Conclusions}

In our original article last November we put forth the following propositions: "the response of economic activity to monetary actions compared with that of fiscal actions is (I) larger, (II) more predictable, and (III) faster." We offered a brief theoretical framework for analyzing the ways stabilization actions influence economic activity, and evidence bearing on the above propositions was presented. Regarding fiscal actions, we concluded that "either the commonly used measures of fiscal influence do not correctly indicate the degree and direction of such influence, or there was no measurable net fiscal influence on total spending in the test period." Regarding monetary actions, we concluded that in view of the finding of a strong empirical relationship be tween economic activity and the measures of monetary actions, greater reliance should be placed on this form of stabilization action.

De Leeuw and Kalchbrenner propose, on statistical criteria only, using "unborrowed reserves," rather than the money supply or the monetary base, as a measure of monetary influence. However, they do not offer any theoretical rationale showing the link between this variable and economic activity, or theoretical superiority of this variable over total reserves, the monetary base or the money supply. We have argued that on theoretical grounds unborrowed reserves is not a relevant measure of monetary influence. De Leeuw and Kalchbrenner offer statistical criteria for use of unborrowed reserves as their exogenous monetary measure, but they do not present any evidence indicating whether this variable meets their criteria. We have presented tests which show that unborrowed reserves do not meet their criteria for acceptability on statistical grounds.

Our critics have shown similarities between the results they obtained by using "unborrowed reserves" (Ru) as a measure of monetary influence and the results from the Federal Reserve Board-M.I.T. econometric model which uses similar variables. In view of the serious reservations we have presented regarding the use of unborrowed reserves as a measure of monetary influence based on both theoretical and statistical criteria, we have considerable doubt as to the desirability of using this monetary variable in econometric models of the U.S. economy.

Leonall C, ANDERSEN JERRY L. JORDAN

The Comment and Reply are available as Reprint No. 37 . 